\title{
Alta Dirección Pública
}

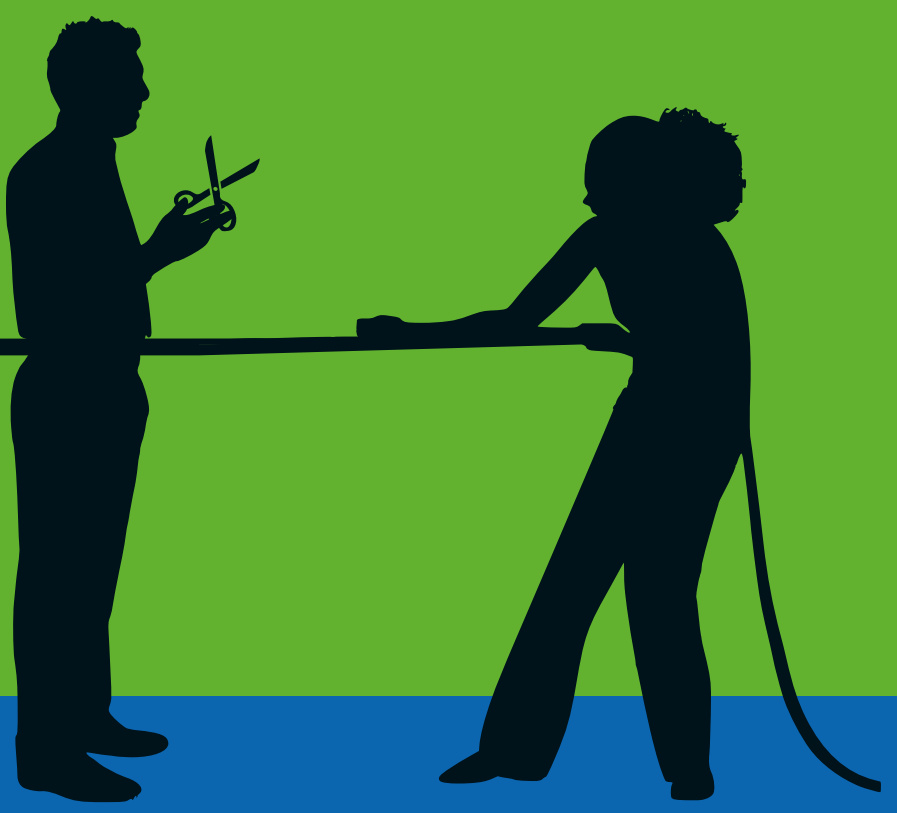

\section{Otra vez la Confianza}
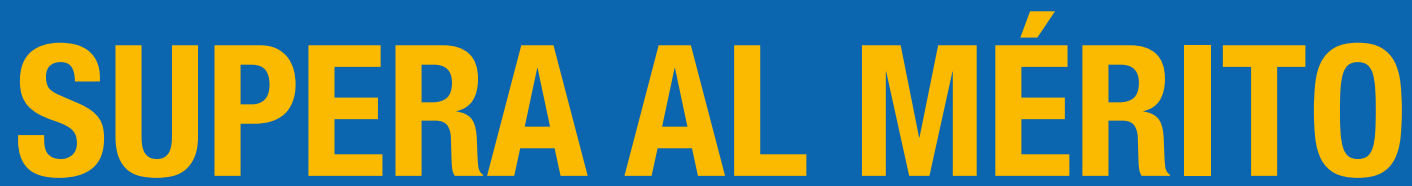

Los resultados luego de un año de gobierno no son alentadores. Los egresos no voluntarios o por no renovación, que implican una acción deliberada de la autoridad respecto de la continuidad de un directivo de primer nivel no cambiaron, más bien se han mantenido.

Eduardo Abarzúa C. Ph.D. en Ciencias del trabajo, Universidad Católica de Lovaina, Bélgica. Decano, Facultad de Economía y Negocios, Universidad Alberto Hurtado. Consejero del Consejo de Alta Dirección Pública.

Manuel Inostroza P., Médico cirujano, Máster en Salud Pública, Universidad Johns Hopkins, USA. Decano, Facultad de Medicina y Ciencia, Universidad San Sebastián. Consejero del Consejo de Alta Dirección Pública.

e ha cumplido un año del tercer cambio de coalición de gobierno y como habíamos señalado en un artículo anterior, se trataría de una prueba de fuego para el Sistema de Alta Dirección Pública (SADP), en particular respecto de ponderar el efecto de la reforma legal del 2016.

Esta reforma buscó a grandes rasgos quitar algunos "incentivos" existentes que facilitaban, por razones de confianza, egresos masivos de altos directivos públicos en los cambios de coalición. Es así como se eliminó la figura de los cargos transitorios y provisionales (TyP), se facultó al Presidente de la República para que dentro de los tres primeros meses de gobierno pudiera nombrar hasta 12 jefes de servicio sin otro requisito que cumplir con el perfil del cargo previamente aprobado por el Consejo de Alta Dirección Pública. También se estableció la obligación de la autoridad de informar al Consejo en forma previa, fundada y por escrito respecto a su decisión de desvincular directivos de segundo nivel jerárquico en los primeros seis meses de gobierno, facultándolo para citar a la autoridad a informar sobre sus fundamentos, $y$ se limitó la posibilidad de llevar a cabo concursos en los últimos 8 meses de gobierno. En alguna medida se buscaba reequilibrar nuestra formula mérito-confianza.

\section{SE MANTIENE LATASA DE JEFES DE SERVICIO QUE SALEN DE SUS CARGOS PERO AUMENTAN EN NÚMERO}

Los resultados luego de un año de gobierno no son alentadores. Tal como muestra el gráfico siguiente, los egresos no voluntarios o por no renovación, que implican una acción deliberada de la autoridad respecto de la continuidad de un directivo de primer nivel no cambiaron, más bien se han mantenido: en cada cambio de coalición y luego de un año de ejercicio de gobierno se desvincula en promedio casi un $70 \%$ de los jefes de servicio. Peor aún, si más allá de tasas, se miran directivos cesados en el primer año de cada gobierno la cifra va en aumento: 51 en el primer gobierno de Piñera, 57 en el segundo de Bachelet y 66 en el primer año de la actual administración.
I Nivel, Cantidad de egresos por Término de período y No Voluntario

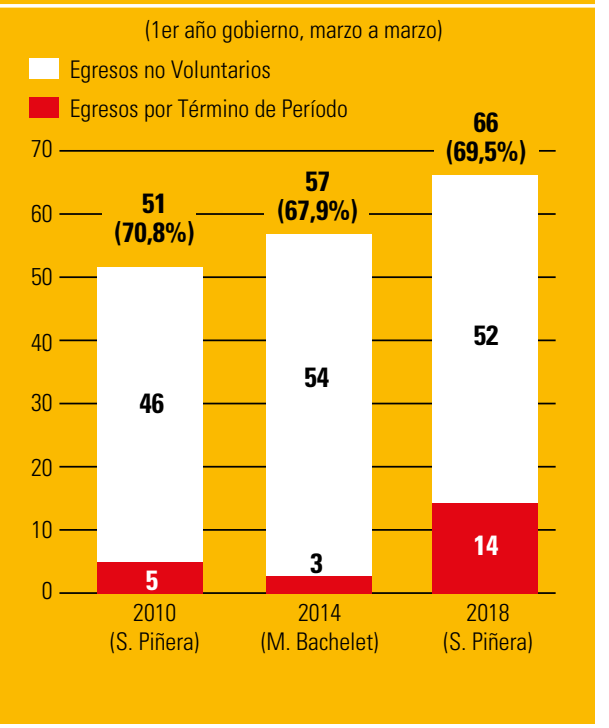

Fuente: Dirección Nacional de Servicio Civil, 2019

\section{Observatorio Económico}


Resulta evidente que los cambios legislativos no lograron contrapesar la desconfianza respecto de los directivos que no han sido nombrados por la coalición entrante. Se pensaba que la ausencia del TyP compensada con los 12 nombramientos anticipados, sería un efectivo freno a las desvinculaciones masivas, sin embargo, no hubo efecto alguno. Tampoco fue un instrumento eficaz la facultad entregada al Consejo de Alta Dirección Pública de suspender la obligación de efectuar concursos en los últimos 8 meses de un gobierno: en el período que se inició el 11 de julio de 2017 y finalizó el 11 de marzo de 2018, se presentaron 43 solicitudes de concurso de I y II nivel, respecto de las cuales el Consejo otorgó su acuerdo en 24 oportunidades (54\% del total).

\section{AUMENTAN LOS DIRECTIVOS CESADOS DEL SEGUNDO NIVEL Y AUMENTAN LOS DIRECTI- VOS QUE TERMINAN SU PERÍODO}

Respecto de los directivos de II nivel hay más elementos que analizar, los egresos para este grupo en el primer año de gobierno del presidente Piñera pasaron de $34 \%$ el 2010 a un 47,1\% el 2018. Esta última cifra fue algo inferior al $51,3 \%$ que sacó Bachelet durante el primer año de su gobierno, sin embargo en número de totales también se observa un aumento de directivos cesados en sus funciones, de 301 a 329.

Un dato en que vale la pena detenerse es el aumento de egresos que se producen entre el primer y segundo gobierno de Piñera. Tal parece que la ausencia delTyP no limitó los egresos de directivos, más bien hizo convivir la salida y los concursos de directivos de I y II nivel.

\section{Nivel, Cantidad de egresos por}

Término de período y No Voluntario

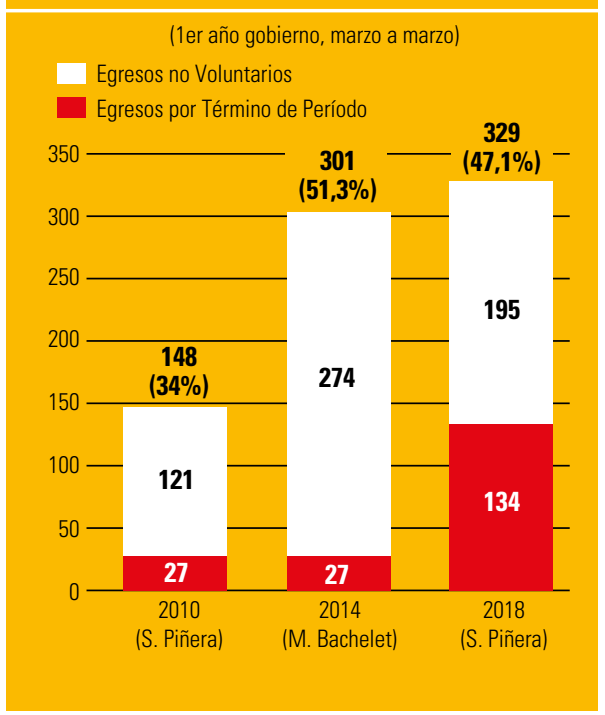

Fuente: Dirección Nacional de Servicio Civil, 2019
"En cada cambio de coalición y luego de un año de ejercicio de gobierno se desvincula en promedio casi un $70 \%$ de los jefes de servicio",

Respecto de la obligación de notificar al Consejo las desvinculaciones de directivos de segundo nivel jerárquico durante los primeros 6 meses de gobierno, pudiendo la autoridad ser citada a exponer los motivos y/o cumplimiento del convenio de desempeño, se informó al Consejo de un total de 144 desvinculaciones, de 45 servicios públicos. Sin embargo, se trató de notificaciones posteriores a la decisión, que fundadas en la exclusiva confianza no requieren hacer referencia al desempeño, volviéndose un mero trámite y no una auténtica dificultad para las desvinculaciones.

Finalmente, un elemento interesante surge al analizar los datos, se trata del aumento del número de directivos que cumplen un período y luego son cesados en sus cargos. Lo anterior, es probablemente uno de los pocos efectos de la reforma que, ante la imposibilidad de nombramientos directos, hace más razonable esperar a completar períodos mientras se realizan los concursos del I nivel jerárquico u otros del mismo nivel considerados más críticos.

TODO EL MUNDO DICE QUERER EL SISTEMA PERO SIGUE SIENDO MÁS IMPORTANTE LA EXCLUSIVA CONFIANZA, CASI SIEMPRE TRADUCIDA EN AFINIDAD POLÍTICA

Ante estas cifras la conclusión parece demasiada obvia: el mundo político convive de manera ambivalente con el sistema, se promueve el mérito y la objetividad en los procesos de selección como la fórmula para elegir a los mejores líderes para ejecutar las políticas públicas, sumando nuevas instituciones e incluso otros poderes del estado al sistema. Pero al mismo tiempo se desconfía de aquellos que no han sido nombrados por la propia coalición, y se usa al máximo la discrecionalidad para el despido de aquellos que no se nombró. En los hechos, es la idea que el SADP es un instrumento que selecciona profesionales idóneos pero políticamente cercanos a cada coalición política. Por lo mismo, cuando se accede al poder no hay interés en apreciar la calidad de los desempeños de quienes ocupan cargos provistos por el SADP, sino más bien esclarecer la exclusiva confianza, que no es más que la simple cercanía política. Por lo demás, cuando la sobre politización hace que los argumentos y las campañas se construyan sobre la evaluación negativa de la gestión del adversario, solo por razones de consistencia cuando se accede al gobierno, el despido de directivos es la única alternativa.

\section{SÓLO QUEDA AVANZAR EN DAR REAL RELE-} VANCIA AL MÉRITO $O$ EL SADP SE PERDERÁ

El efecto de la ley se probó en el primer año de gobierno y los resultados no son los esperados. La pregunta que surge es por el modelo o más sencillamente por lo que queremos del Sistema de Alta Dirección Pública. En la inspiración de la Reforma del 2016, los discursos y las ampliaciones que ha tenido el sistema resulta claro que el foco debe estar en dar mayor relevancia al desempeño, como contrapeso a la invocación de la exclusiva confianza como fundamento para decidir la continuidad o no de un directivo. Si ese es el foco, la Reforma no logró su propósito principal y los datos son elocuentes.

Para avanzar estamos convencidos que el sistema se consolidará limitando la total discrecionalidad vigente para desvincular directivos. Lo anterior sólo se alcanza reforzando técnica e institucionalmente el convenio de desempeño. Allí sólo queda establecer un contrapeso real en una institución como el Servicio Civil que analice y valide dicho instrumento y sus resultados, al mismo tiempo, que sea el referente para fundar la movilidad de directivos, superando la idea del desempeño sólo como herramienta binaria para sustentar despidos. Por ahora el sistema atrae muy buenos postulantes y las nóminas son de alta calidad, quienes resultan elegidos son los mejores.

En el primer nivel jerárquico, más que seguir entregando cargos a la discrecionalidad del nombramiento, las medidas que se requieren deben ir en la dirección contraria. Existen demasiados servicios cuyos resultados son estables y no cambiarán según la coalición política, el Servicio de Registro Civil es un buen ejemplo. Ha llegado el momento de identificar y diferenciar instituciones de acuerdo con criterios como el señalado para de manera decidida ponderar los desempeños en vez de las afinidades políticas a la hora de decidir la continuidad o no de sus directivos. Para el segundo nivel jerárquico el tema parece más sencillo, las desvinculaciones deben fundarse exclusivamente en la evaluación de los convenios de desempeño.

No podemos esperar hasta un nuevo cambio de coalición para hacer estas correcciones, la Alta Dirección Pública es mucho más que un proceso concursal. $\mathbf{E}$ 